\title{
Literatura
}

\section{ABBOTT Y COSTELLO}

Sergio Ramírez ${ }^{1}$

\author{
Cuento inédito, parte del próximo libro del Dr. Sergio Ramírez Mercado, \\ FLORES OSCURAS, que aparecerá en Alfaguara en el presente año.
}

Recibido: 02 de septiembre de 2012 / Aceptado: 13 de diciembre de 2012

\section{RESUMEN}

Abbott y Costello es un cuento basado prácticamente en su totalidad, en la vida real. El caso del nicaragüense Natividad Canda, muerto por perros rottweiler en San José, Costa Rica ante la presencia $\mathrm{y}$ negligencia de celadores del lugar y policías. El caso estremeció la opinión pública de los dos países.

Un excelente cuento basado en un caso extremadamente dramático de la vida real que nos llama la atención sobre la suerte del migrante.

Palabras clave: Natividad Canda, rottweiler, muerte, policía, opinión pública.

\section{ABSTRACT}

Abbott y Costello is a story based almost entirely on real life. It's the case of Nicaraguan Natividad Canda, killed by two rottwieler dogs in San Jose in the presence of and neglegence of watchman and police. The case shook public opinion in both countries.

An excellent story based on an extremely dramatic real life event that brings out attention to the plight of the migrant.

Key words: rottweiler, death, police, public opinion.

\section{Los hechos.}

N atividad Canda Mairena, de 25 años de edad, murió la madrugada del jueves 10 de noviembre del año 2005 destrozado por dos perros rottweiler que lo atacaron a mordiscos.

Los brazos, los codos, las piernas, los tobillos, el abdomen y el tórax resultaron desgarrados. Las heridas en los codos y tobillos fueron tan profundas que dejaron expuestos los huesos. Cuando después de cerca de dos horas de hallarse a merced de los perros fue al fin liberado, sus palabras habrían sido, según testigos, "échenme algo encima que tengo frío", o "échenme una cobija que tengo frío". Tiritaba de manera incontrolable. Llegó aún con vida al hospital Max Peralta de la ciudad de Cartago, pero falleció minutos después de haber ingresado a la sala de emergencia a consecuencia de la abundante pérdida de sangre.

A eso de las 12.20, pasada la medianoche, Canda había saltado de manera furtiva el muro perimetral de las instalaciones del taller de automecánica La Providencia, situado en La Lima de Cartago, cerca del puente de Los Gemelos, en compañía de Carlos Andrés Rivera, alias "Banano", con intenciones de robar, según el reporte policiaco. Los dos animales se

1 Sergio Ramírez (1942). Autor de Castigo divino (1988), Premio Dashiel Hammet de Novela Negra en España; Un baile de máscaras, Premio Laure Bataillon a la mejor novela extranjera traducida en Francia en 1998; Margarita, está linda la mar, Premio Internacional Alfaguara de Novela con en 1998, por la que también recibió el Premio Latinoamericano José María Arguedas en La Habana en 2000. También ha publicado, entre otros libros, Cuentos completos, con un prólogo de Mario Benedetti (1998); Mentiras verdaderas, ensayos sobre la creación literaria, (2001); Catalina y Catalina, cuentos, (2001); Sombras nada más, novela, (2002), Mil y una muertes, novela, (2004); El reino animal, cuentos (2006); El cielo llora por mí, novela, (2009), La Fugitiva, novela, (2011. En 2011 recibió en Chile el Premio Iberoamericano de Letras José Donoso por su obra literaria. En 2013, Alfaguara publicará su nuevo libro Flores Oscuras, al cual pertenece el cuento Abbott y Costello. 


\section{Literatura}

concentraron sólo en atacar a Canda, pues Rivera consiguió huir saltando otra vez el muro. Fue capturado posteriormente y llevado a la cárcel de Cartago.

Juan Francisco Picado, guardián de turno, fue quien liberó a los perros cuando se dio cuenta de la presencia de extraños. "Por lo general se les deja sueltos desde las nueve, pero esa noche se esperaba la llegada de un camión que debía ser reparado al día siguiente, y por eso permanecían encerrados en su jaula", dijo.

Requerido por teléfono, el dueño del taller, Alejo Sanabria, se presentó cerca de las 12.40 a.m., pues tiene su casa de habitación en las cercanías. Como veinte minutos después, cerca de la una de la madrugada, se presentaron a bordo de dos camionetas de tina ocho agentes de la Fuerza Pública. El sargento Feliciano Ortuño, jefe de la patrulla, declaró que estudiaron la situación y resolvieron no disparar contra los perros

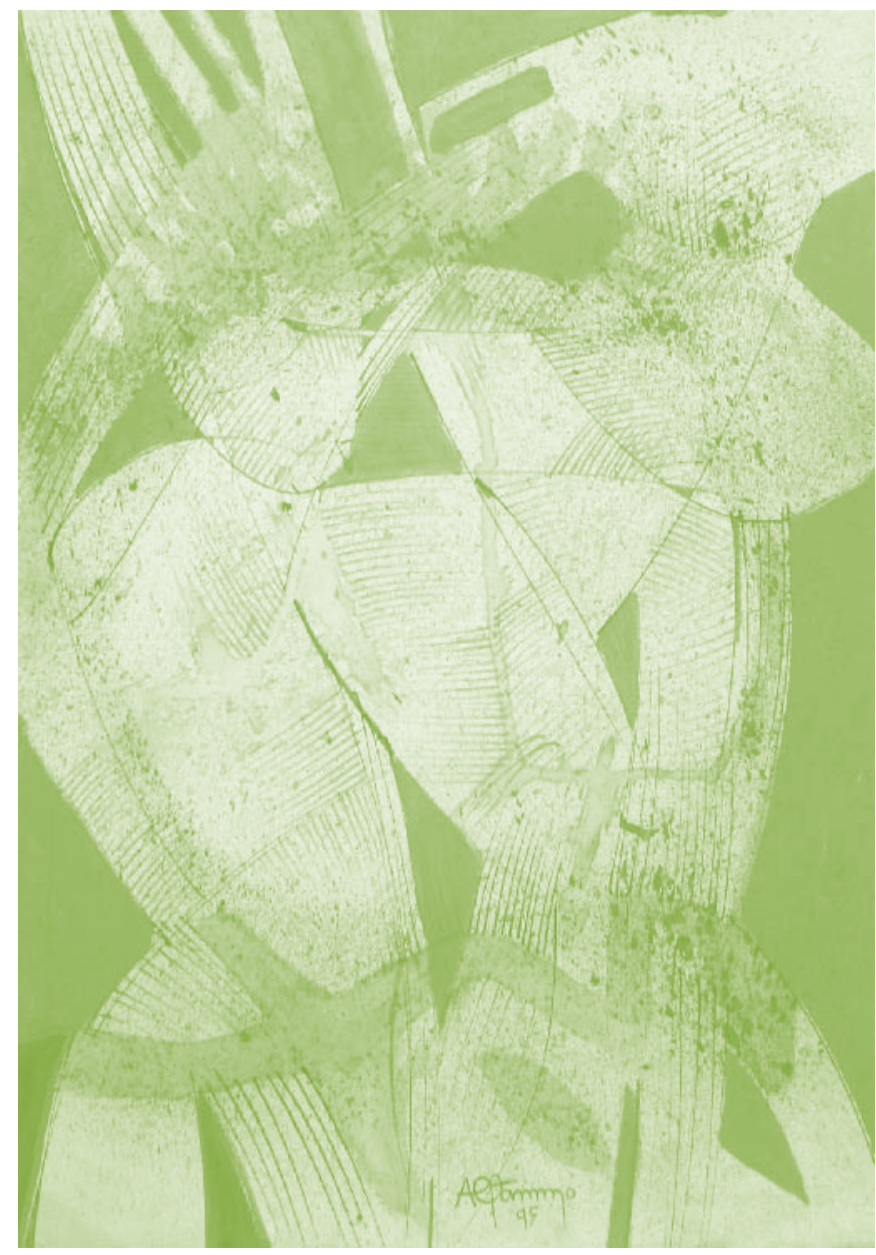

porque temían herir a Canda; lo mismo afirmó Manuel Goyzueta, el otro de los guardas de seguridad, quien mostró a los periodistas jirones del pantalón de la víctima: "hice seis disparos al aire para asustarlos, pero pasó todo lo contrario, se enfurecieron más". Uno de los perros se llama Abbott, el otro Costello. Según Goyzueta, fue Abbott el que atrapó a Canda y lo arrastró una distancia de 25 metros.

El intento de rescate por parte de la Cruz Roja y del Cuerpo de Bomberos no empezó sino a la 1.40 de la madrugada. Según el socorrista Andrés Quirós, se utilizó un total de 3.786 litros de agua a presión, y fue gracias al poder de las mangueras que los perros por fin retrocedieron.

Los dos rottweiler volvieron a la jaula por sus propios pasos después que Canda fue llevado al hospital, y quedaron encerrados de nuevo. Cada uno tiene un costo aproximado de quinientos dólares, según peritos consultados. El Ministerio de Salud de Costa Rica decidió que no serían sacrificados, luego de verificar que no padecían de rabia.

La licenciada Valentina del Socorro Camacho, veterinaria y experta en conducta animal, explicó el motivo por el que los Rottweiler no obedecieron las órdenes de detenerse, una vez que tenían cercada a la víctima. "Los perros se hallaban fuera de control, pues cuando atacan en jauría se acentúa en ellos el instinto de atrapar a la presa. Cuando se enfrenta el ataque de dos o más animales de esa clase, no hay probabilidades de sobrevivir".

Hay un video que alguien tuvo tiempo de tomar, donde se registra el ataque. Puede verse en YouTube, http:// www.youtube.com/watch?v=YKrqZpD6VmI. Ambos animales son de color negro, la piel lustrosa, y a luz de un fuerte foco que dispersa la oscuridad de la noche, se afanan si descanso encima del cuerpo de Canda tendido sobre la hierba crecida, mientras un hombre de chaqueta marrón, que bien puede ser uno de los guardas del taller, o el dueño, permanece de espaldas a unos pocos pasos. Luego el cuerpo es arrastrado de un lado a otro por los perros, y más luego uno de ellos está ocupado en clavar sus colmillos en la víctima, en tanto el otro vigila con la cabeza enhiesta. No se sabe cuál es Abbott y cuál es Costello. El hombre de la chaqueta 


\section{Literatura}

marrón se mantiene en escena, siempre de espaldas.

\section{El occiso.}

Natividad Canda Mairena nació el13 deagosto de1980 en Chichigalpa, departamento de Chinandega, en el occidente de Nicaragua, donde las temperaturas en tiempo de verano alcanzan los $40^{\circ}$ grados centígrados. Son las tierras más fértiles del país, situadas en una planicie que se extiende entre la cordillera volcánica de los Maribios y la costa del océano Pacífico, aptas para el cultivo de la caña de azúcar, el maní, la soya, el banano y el ajonjolí. Antiguamente se sembraba también algodón, cultivo que envenenó sin remedio las fuentes de agua,

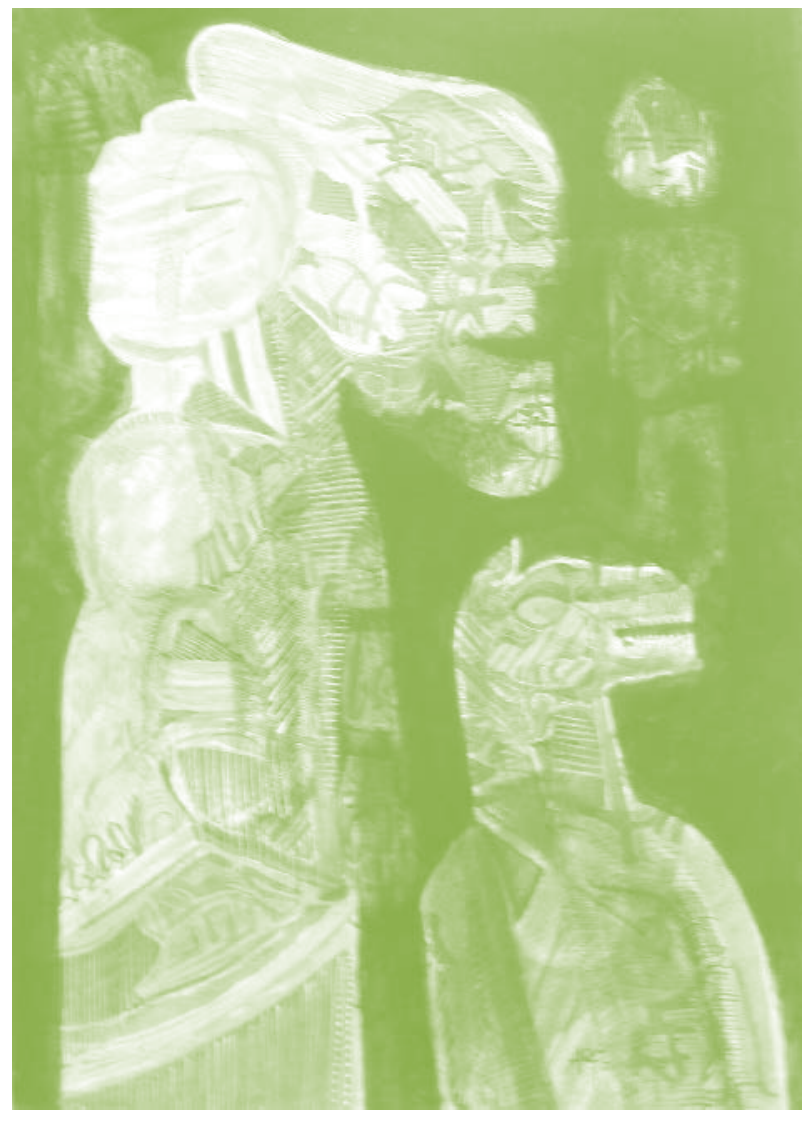
pues los sedimentos de los insecticidas penetraron el manto freático, de modo que hasta la leche materna se halla contaminada de toxaclorofeno.

Su familia vive actualmente en el reparto "Modesto Palma" de Chichigalpa. Natividad era el menor de nueve hermanos y permanecía soltero. Su padre murió debido a una deficiencia renal crónica, provocada por la constante deshidratación a que se someten los cortadores de caña de azúcar que realizan su trabajo a pleno sol, y después que los cañaverales han sido quemados, con lo que la temperatura sube aún más.

La responsabilidad de sostener la casa quedó en manos de su mujer Juana Francisca Mairena. Para poder mantener a sus hijos trabajó también cortando caña como cualquiera de los hombres de las cuadrillas, y como empleada doméstica, cocinando, lavando y planchando. En 1993 dos de ellos, Antonio, de 20 años, y Natividad que tenía entonces 13, decidieron buscar fortuna en Costa Rica, igual que otros miles de emigrantes ilegales.
Según su hermano César Augusto, Natividad fue deportado varias veces pero siempre volvía a atravesar la frontera por los puntos ciegos que conocía como la palma de su mano. Para él eso era como un deporte. "Que me voy a quedar haciendo aquí si sólo voy a ser una boca más que alimentar", les decía en cada ocasión que regresaba sólo para volverse a ir. Lo buscaban al amanecer, y ya no estaba. Era terco de carácter. "La verdad es que en Nicaragua, además de que no abunda el trabajo, se gana una poquedad. En Costa Rica hay mejores salarios, y la gente se va con esa esperanza", agrega César Augusto, cortador de caña igual que sus padres, y quien, mientras no empieza la zafra en el ingenio azucarero vecino, pasa todo el día, como él mismo dice, "sosteniéndose la quijada".

Juana Francisca Mairena tenía 68 años a la muerte de Natividad. Enjuta, encorvada, oscura de piel como si el sol la hubiera consumido y calcinado, las rudezas de la vida la hacen aparecer más vieja, aunque son pocas las canas en su pelo. Cuatro de sus hijos, Margarito Esteban, de 38 años, César Augusto de 36, Juana Francisca, de 35, y María Esperanza de 32, viven en la misma calle del reparto. La calle carece de pavimento y tiene más bien el aspecto de un cauce de lluvia donde crece libremente la maleza.

Tras muchos trámites la familia consiguió que los restos de Natividad fueran repatriados. Juntando a como pudieron los centavos, la madre viajó a traerlos. Llegaron en un ataúd recubierto de peluche color gris.

Al cumplirse el primer aniversario de su muerte se celebró una misa en la parroquia de San Blas. A esa 


\section{Literatura}

fecha, tanto la madre como las hermanas guardaban aún riguroso luto. "Nunca estuvo solo, pero lo dejaron morir, dos horas enteras con esas dos fieras despedazándolo y nadie quiso quitárselas de encima, vea qué pecado", dice su hermana María Esperanza mientras sacude con desconsuelo la cabeza, sentada en una silla tejida de plástico en la vivienda de su madre. Es una casa forrada de tablas a la que se llega subiendo un barranco. A través de las rendijas de las tablas se escapa el humo del fogón de la cocina. Por ese barranco bajó el ataúd de peluche para ser llevado al cementerio de Chichigalpa, cargado por los vecinos.

Se dieron cuenta del suceso por una llamada telefónica de Antonio, que trabaja en un supermercado de San José. Nada más les comunicó que Natividad estaba muerto, pero no se atrevió a decirles que había sido destrozado por unos perros. Eso lo supieron hasta que vieron las imágenes que estuvo pasando la televisión en Nicaragua. "No podíamos creer que fuera él ese muñeco de trapo que los perros zarandeaban de aquí para allá a su placer", dice María Esperanza.

"Mi hermano le tenía pánico a los perros", agrega. "El temor le quedó desde pequeño, cuando un animal que parecía manso, un pastor alemán, lo mordió en la cara y lo dejó marcado con una cicatriz. El perro estaba amarrado en la puerta de la casa de uno de los técnicos de las calderas del ingenio, y él se acercó con toda inocencia a hacerle jugarretas. Natividad andaba entonces en los ocho años, acababa de dar su primera comunión en la iglesia de San Blas. Esa vez, mi mamá lo llevó después de la misa al parque de Chichigalpa para que un fotógrafo ambulante le tomara una foto, vestido de blanco y con su gran candela en la mano, más grande que él".

"A mi mamá le dijeron unos vecinos del taller, que mientras los perros revolcaban y mataban a tarascadas a mi hermano, unos policías de los que habían llegado se quedaron viendo la escena de lejos, y otros se volvieron a la radiopatrulla donde se pusieron a oír radio", dice otro de los hermanos, Margarito Esteban, y dice también: "cuando publique esto haga constar que le estamos muy agradecidos al licenciado Sotela, el abogado que hizo la acusación sin cobrar un centavo, viendo la pobreza de mi mamá".

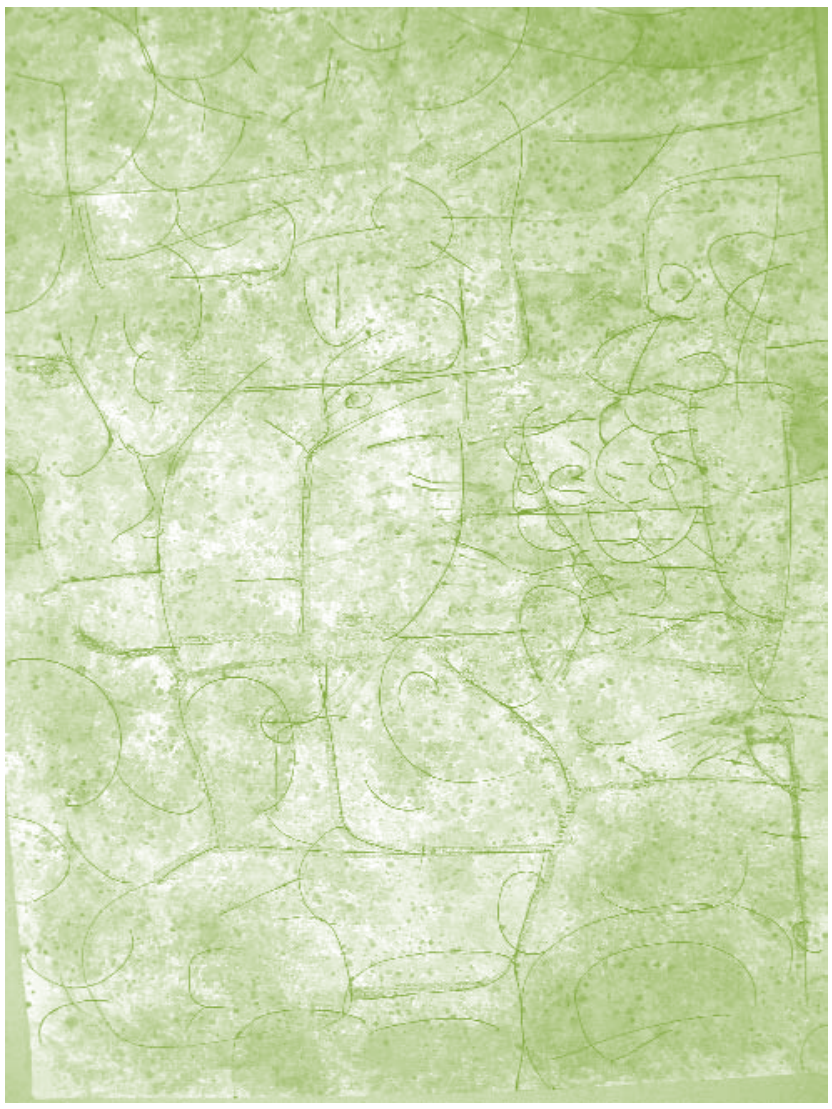

Harold Fallas, un amigo costarricense de Natividad, recuerda que éste solía dormir debajo de los puentes, o donde le cogiera la noche, y para que nadie fuera a denunciarlo como indocumentado se fingía tico al hablar, y decía que su familia era de Tres Equis de Turrialba. En Los Diques de Cartago, donde vivió un tiempo, le decían Nati. "Era tranquilo, nada pendenciero", afirma Bautista Lagos, un vecino del lugar.

Según información judicial reunida por el diario La Nación, sólo en el año 2005, el mismo de su muerte, Natividad había comparecido ocho veces ante los tribunales de justicia, señalado como sospechoso de saqueo de vehículos, robo de electrodomésticos en domicilios particulares, asaltos en la vía pública, posesión y consumo de drogas, y sustracción de cables del tendido eléctrico y telefónico. 


\section{Literatura}

\section{El shock hipovolémico.}

Fue ya cuando yacía en la tina de una de las dos camionetas de la Fuerza Pública en que iban a transportarlo al hospital de Cartago, que Natividad Canda dijo: "échenme algo encima que tengo frío", o "échenme encima una cobija que tengo frío". Según el dictamen médico legal fueron 197 las mordeduras identificadas en su cuerpo. Cuánta sangre puede escaparse a través de tantas heridas provocadas por colmillos afilados, en un espacio de casi dos horas, sin ninguna clase de interrupción, es algo que no puede determinarse, pero, en todo caso, resulta más que suficiente para causar un shock hipovolémico.

El shock hipovolémico se da cuando el cuerpo ha perdido una quinta parte o más del volumen normal de la sangre que circula en el cuerpo, y uno de sus principales síntomas es la intensa sensación de frío a causa de la hipotermia profunda, la cual consiste en el descenso de la temperatura corporal por debajo de $31^{\circ} \mathrm{C}$. Ya para entonces la capacidad de bombeo del corazón se encuentra gravemente debilitada, y el funcionamiento de otros órganos vitales se ha entorpecido. Además del intenso frío, se produce un estado de ansiedad al extremo de la angustia, agitación y confusión de los sentidos, temblor incontrolable, y luego debilidad general y pérdida de la coordinación, somnolencia, disminución del ritmo respiratorio y del pulso, hasta llegar al letargo, al estado de coma, y a consecuencia de la baja actividad celular, a la muerte clínica, y de allí a la muerte cerebral.

\section{Los perros.}

El rottweiler macho pesa por lo regular entre 110 y 120 libras, y mide entre 61 y $68 \mathrm{~cm}$ desde la cabeza hasta la cruz. Tiene una constitución musculosa, gran cabeza, cuello también musculoso, de longitud moderada, hocico corto y férreas mandíbulas. La fuerza de su mordida es de 300 libras en el radio de la boca. Está armado de 42 dientes, con cierre en tijera, de modo que los incisivos superiores cubren sin fisuras los inferiores.

Su nariz es bien desarrollada, más ancha que redonda, con fosas nasales relativamente amplias, la trufa siempre negra. Los ojos son de tamaño medio, en forma de almendra, de color castaño oscuro, y las orejas caídas, triangulares, y muy separadas. Si tiene papada o piel colgante en la garganta, es un mal ejemplar. Se le suele cortar la cola cuando cachorro, dejando tan sólo una o dos vértebras, si bien el estándar de la Federación Canina Internacional (FCI) prohíbe la amputación total de la misma.

Aunque el rottweiler es usado para defensa y protección, los manuales de crianza y uso los describen como amistoso, alegre, tranquilo, fiel, obediente, dispuesto al aprendizaje y al trabajo en diversas tareas. En las tablas de clasificación de raza caninas según el grado de agresividad, no se encuentra entre los diez primeros, pero sí se halla entre los diez más inteligentes, criaturas perspicaces y con buen discernimiento. La FCI los considera ideales como guardianes de la familia y de la propiedad.

\section{Reconstrucción de los hechos.}

La noche del viernes 25 de noviembre del 2005, las autoridades judiciales llevaron a cabo la reconstrucción de los hechos en el predio del taller de automecánica La Providencia. Participaron unas cuarenta personas entre jueces, fiscales, técnicos forenses, expertos en balística y planimetría, abogados de las partes, miembros del Organismo de Investigaciones Judiciales (OIJ), los policías de la Fuerza Pública involucrados, así como los socorristas de la Cruz Roja, y los miembros del Cuerpo 


\section{Literatura}

de Bomberos que al fin realizaron el rescate. Dos perros rottweiler amaestrados hicieron las veces de Abbott y Costello, los que en ningún momento abandonaron su jaula mientras duró el procedimiento, y un maniquí hizo las veces de Canda, vestido con ropas parecidas a las que éste llevaba al momento del ataque. Su compañero Carlos Andrés Rivera, alias "Banano" participó él mismo en la representación, lo mismo que el dueño del taller, y los dos vigilantes de turno.

El objetivo definido por el fiscal del caso, licenciado Pablo de Jesús Peralta, para solicitar al tribunal competente la reconstrucción de los hechos en el propio lugar en que acaecieron, fue determinar si mientras Canda estuvo sometido a la agresión de los perros, las personas que en uno $\mathrm{u}$ otro momento se hallaban presentes estuvieron en la posibilidad real de hacer algo efectivo para alejarlos o neutralizarlos, o si, por el contrario, la extrema agresividad que los mismos mostraban constituyó un impedimento insalvable para llevar adelante cualquier iniciativa, incluida la de hacerles disparos de armas de fuego, y si estos disparos hubieran ido o no en perjuicio de la propia víctima.

Los perros, que estuvieron siempre a las órdenes y bajo el cuidado de su entrenador, atacaron al maniquí hasta destrozarlo a mordiscos, desgarrando así mismo sus ropas, mientras las personas involucradas se colocaron en los mismos lugares que declararon tener a la fecha de los sucesos investigados. El procedimiento tuvo menor duración que la de su tiempo real.

\section{La sentencia judicial.}

El licenciado Fernando Sotela, actuando en representación de la señora Juana Francisca Mairena viuda de Canda, interpuso el 15 de noviembre de 2005 una querella ante el Ministerio Público de Cartago, mediante la cual acusó por el delito de homicidio simple en concurso de omisión de auxilio, al dueño del taller La Providencia, Alejo Sanabria, y a los guardas de turno del mismo, Manuel Goyzueta y Juan Francisco Picado. También acusó de la comisión del mismo delito a los ocho agentes de la Fuerza Pública "por su manifiesta impasibilidad".

Por su parte, el fiscal Peralta solamente introdujo acusación penal por omisión de auxilio en contra de dos de los miembros de la fuerza policial, Gamaliel Urbina y Yader Luna, "quienes pese a la urgencia de los hechos se alejaron hacia una de las radiopatrullas y se dedicaron a conversar, a tomar café de un termo, y supuestamente a escuchar un programa musical en la radio".

El Tribunal de Justicia de Cartago, compuesto por las juezas Maribel Zeledón, Clarisa Chan y Rosaura Pacheco, mediante sentencia firme dictada a las diez de la mañana del 14 de enero de 2006, por mayoría de dos votos contra uno eximió de responsabilidad penal al dueño del taller, Alejo Sanabria, y a los guardas de seguridad del mismo, Manuel Goyzueta y Juan Francisco Picado, así como a los ocho agente de la Fuerza Pública, desestimando en todas sus partes la acusación entablada en contra de cada uno de ellos.

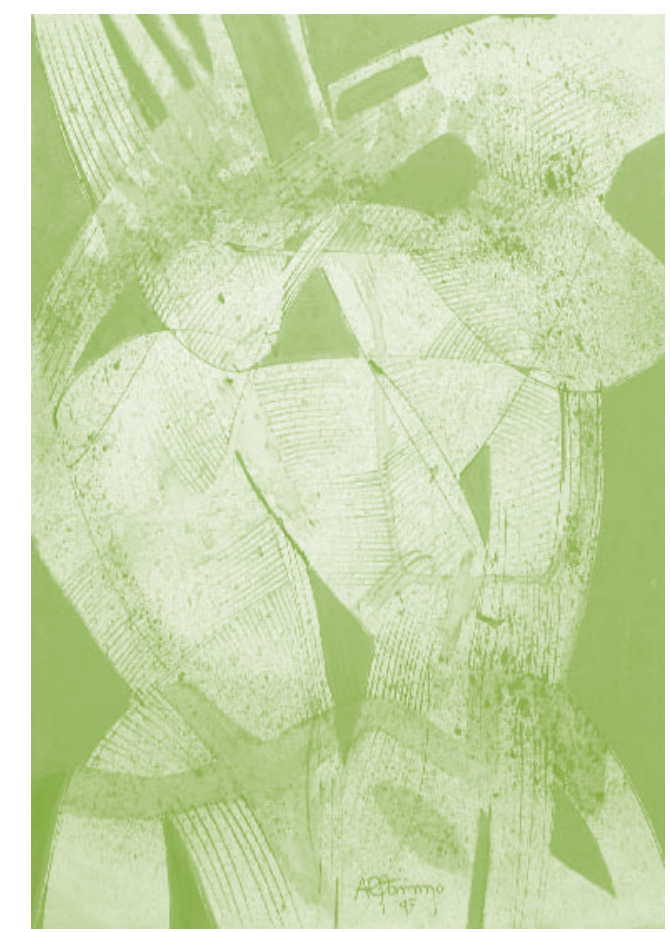

El voto contrario, debidamente razonado, correspondió a la jueza Maribel Zeledón, quien señaló diversas inconsistencias y contradicciones jurídicas en el fallo de mayoría: "se tomó en cuenta como fundamento de la sentencia el dictamen pericial de un médico veterinario, quien afirmó que el salto de un perro rottweiler es más rápido que la velocidad de un disparo, por lo que, según ese criterio, resulta imposible que una bala lo alcance mientras se halle en movimiento, aseveración a todas luces absurda que busca justificar la pasividad de quienes tenían el deber de disparar contra los animales enfurecidos y no lo hicieron, ya 


\section{Literatura}

que una bala de pistola, como las que utiliza la Fuerza Pública, viaja a $340 \mathrm{~m} / \mathrm{s}$, una velocidad parecida a la del sonido, que en la atmósfera terrestre es de 343. $2 \mathrm{~m} / \mathrm{s}$, y que ningún animal por raudo que sea puede nunca alcanzar".

\section{Punto final.}

El acta forense anota que en la morgue del hospital de Cartago fueron retiradas del cuerpo del occiso las siguientes prendas de vestir: "un par de zapatos deportivos de color blanco en mal estado, un par de calcetines verdes, un pantalón jean con considerables desgarraduras, un cinturón de vaqueta, una camiseta de algodón color celeste con logo de Cáritas Internacional, todas con copiosas manchas de sangre".

En la misma acta se registra que en uno de los bolsillos traseros del pantalón se encontró una cartera de material plástico conteniendo tres billetes de cincuenta colones cada uno, una tarjeta de prepago para llamadas telefónicas, y, doblada en dos, la foto bastante apagada de un niño que sostiene una candela de primera comunión.

Managua, enero 2012.

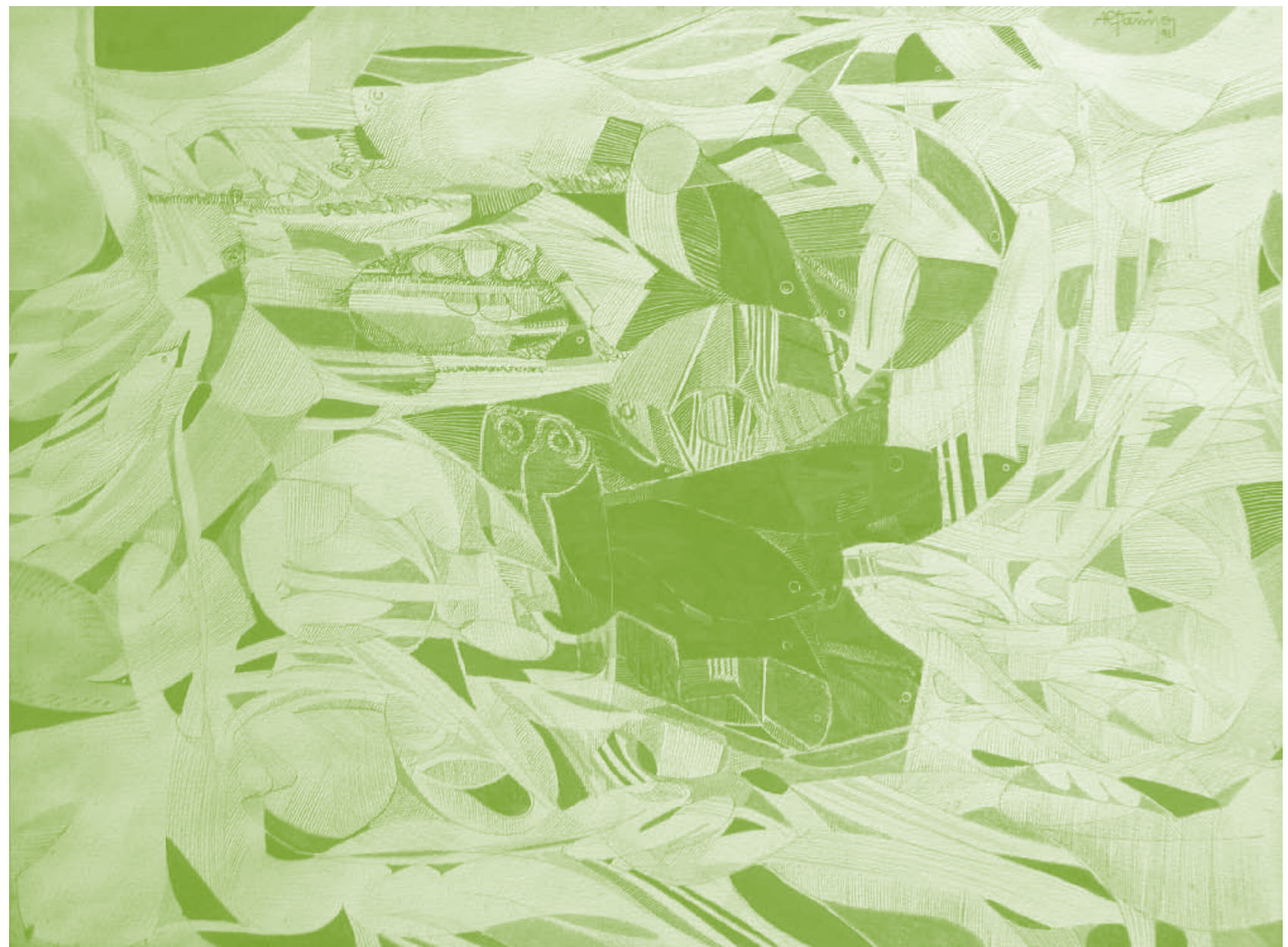

